\title{
TENSILE STRENGTH OF GOMPRESSED SNOW FORMED ON ROADS
}

\author{
By T. Nakamura, H. Nakamura, M. Higashiura and O. Abe \\ (Shinjo Branch, National Research Center for Disaster Prevention, Shinjo, Yamagata-ken, \\ Japan)
}

Abstract. Tensile fracture strengths of fine-grained compressed high-density snow, of compressed and metamorphosed high-density snow-ice, of fine-grained naturally settled snow, and of snow-ice artificially made from the settled snow by freezing with absorbed water, were obtained at constant deformation speeds (constant strain-rates) in a temperature range of 264 to $270 \mathrm{~K}$. No remarkable temperature dependence of fracture stresses was observed in this temperature range. A critical deformation speed in a tensile test above which all the snow samples, except settled snow, fractured, was $4.2 \times 10^{-7} \mathrm{~m} \mathrm{~s}^{-1}$. The fracture strength $\sigma$ (in $\mathrm{N} \mathrm{m}^{-2}$ ) varied with snow density $\rho\left(\mathrm{kg} \mathrm{m}^{-3}\right)$ as $\sigma=2.5 \times 10^{4} \times 1.0046^{\rho}$. In a power-law relationship between strain-rate and maximum stress, $\dot{\epsilon} \propto \sigma^{n}$, the constant $n$ obtained was $5 \cdot 3$ for all the unfractured snow samples.

\section{USING LINEAR DISGRIMINANT ANALYSIS TO CLASSIFY SNOWFALL SITUATIONS INTO AVALANCHING AND NON-AVALANGHING ONES}

\author{
By N. F. Drozdovskaya \\ (Central-Asian Regional Research Hydrometeorological Institute, Observatorskaya 72, \\ Tashkent, GSP 700ooo, U.S.S.R.)
}

Abstract. The existing methods of predicting avalanche danger often do not meet users' demands because of the empiric character of the insufficient volume of information used. In such forecasts the contribution of each individual parameter into the prognostic information is unknown, and this is very important when studying such an event as avalanche formation, which is conditioned by a complex interaction of numerous factors, including snow accumulation, the state of snow thickness, and the conditions of its development.

It is obvious that such problems can be successfully solved by statistical methods, and that explains the growing interest in numerical methods of avalanche forecasting. Problems of multi-dimensional observations arises in many scientific fields. The method suited for this problem is discriminant analysis, the purpose of which is to divide a multi-dimensional observation vector into predetermined classes.

This study considers the prognostic (diagnostic) problems of fresh-snow avalanches released during snowfall or in the two days after it has ceased. The theoretical basis is a complex of statistical methods: correlation and dispersion analysis, "sifting" for the choice of predictors' informative groups, construction of linear parametric discriminant functions, predictions based on training sample, and verification of discriminant functions based on independent material.

The archive used in the study consisted of 500 avalanching cases and I 300 non-avalanching ones. All situations were grouped according to geomorphological characteristics. Each 
situation is described by eight meteorological characteristics. The results of classification of snowfall situations into avalanching and non-avalanching ones are as follows: reliability of $\rho$ is from $75 \%$ to $91 \%, H$ from 0.15 to $0.5 \mathrm{I}$; based on independent material the reliability of $\rho$ is from $63 \%$ to $85 \%, H$ from 0 . Io to 0.56 .

This paper has been accepted in revised form for publication in a later issue of the Fournal of Glaciology.

\title{
IGING RATE ON STATIONARY STRUCTURES UNDER MARINE GONDITIONS
}

\author{
By K. ITAGAKI \\ (U.S. Army Cold Regions Research and Engineering Laboratory, Hanover, \\ New Hampshire 03755, U.S.A.)
}

Abstract. Icing on stationary structures is an increasingly serious problem as off-shore drilling operations in the sub-polar regions becomes more popular. Since this problem is less complicated than icing on a ship, an attempt was made to calculate accretion rate using existing data.

The rate of ice accumulation $R$ can be calculated from $R=C_{\mathrm{f}} C_{\mathrm{c}} F$ where $F$ is the mass flux of the water drops and $C_{\mathrm{f}}$ and $C_{\mathrm{c}}$ are the proportions of spray frozen on the surface and coefficient of capture of drops, respectively. $C_{\mathrm{c}}$ can be close to unity for larger drops such as sea spray. Although many other factors may contribute, $C_{\mathrm{f}}$ seems to be a strong function of the air temperature.

Mass flux can be written as $F=\frac{4}{3} \pi \rho \int n(r) V r^{3} \mathrm{~d} r$ where $n(r)$ is the number of drops of radius $r$ in unit volume, $V$ is the wind velocity, $\rho$ is the density of water; $n(r)$ is a function of wind velocity and height of observation. For a stationary structure, the mass flux is primarily dependent upon the wind speed.

The ice accretion rate $R$, calculated using published data on the size distribution of sea spray and using a capture efficiency $C_{\mathrm{c}}$ of I agrees surprisingly well with the diagrams given by previous authors for icing on ships. 